\title{
Desarrollo y cooperación
}

Green, Duncan, KING, Richard y MillerDAWKINS, May (2010) The Global Economic Crisis and Developing Countries, OXFAM (Research Report, mayo 2010), 72 pp.

Un equipo de OXFAM Internacional ha realización esta investigación, de tipo cualitativo, sobre el impacto de la crisis económica global en 12 países (los países seleccionados fueron los siguientes: Armenia, Burkina Faso, Camboya, Ecuador, Ghana, Indonesia, Nicaragua, Filipinas, Thailandia, Vanuatu, Vietnam y Zambia), además de estudios y análisis regionales de África, Latinoamérica, Asia del sudeste y el Pacífico. Se entrevistó a unas 2.500 personas, con el objetivo de averiguar el impacto de la crisis económica, así como el grado de "resiliencia" lo capacidad de la gente, de las instituciones etc. de resistir y absorber los choques de la crisis), y la vulnerabilidad de las poblaciones de estos países y regiones a la actual crisis global.

Los hallazgos del estudio, en el que han colaborado un número elevado de expertos e instituciones, son muy interesantes. Sorprende que ciertas cosas que se esperaban que ocurrieran, partiendo de la experiencia de anteriores crisis, no han ocurrido; por el contrario, han sucedido cosas que hasta ahora no habían ocurrido. En un número sorprendente de casos, los emigrantes no han vuelto a sus aldeas; las remesas de los trabajadores emigrados han seguido llegando; los hogares han sido capaces de alimentarse a partir de sus jardines o pequeñas fincas; mucha gente pudo mantener su empleo, aunque con menores salarios, menos horas y peores condiciones de trabajo; las familias han sido capaces de seguir enviando sus niños a la escuela etc.
Pero en los lugares en que se descubrieron esos sorprendentes niveles de "resiliencia" se habían dado condiciones "pre-crisis" tales como: presencia de redes sociales de protección; estructuras económicas adecuadas con sistemas fiscales que funcionan gracias a un papel preponderante del Estado, actuando de forma correcta; y por fin, políticas sociales que incluyen enseñanza y sanidad gratuitas, etc.

Sin embargo, el estudio demuestra que la "resiliencia", sea nacional sea individual, tiene sus límites. Una vez que se han agotado, los ahorros necesitan años para recuperarse; las horas extras en un tercer empleo dejan una herencia de agotamiento; los préstamos para el consumo se acumulan formando una pesada deuda para el futuro; y la falta de alimentos en muchos casos compromete la salud y la capacidad de los niños a lo largo de toda su vida. Es claro, además, que son muchas las mujeres que pagan un precio particularmente alto mediante un plus de trabajo no remunerado para mantener a sus hogares.

El estudio incluye un análisis por grandes áreas; en cada una de ellas se presenta un panorama regional; sendos análisis sobre la economía financiera, la economía productiva formal y la economía productiva informal; un apartado sobre migraciones y remesas; otro sobre la economía reproductiva y los impactos a nivel de hogares; y una enumeración de las fuentes de vulnerabilidad y de "resiliencia" en cada caso.

Se concluye con una serie de interesantes lecciones para el futuro: hacer planes para las crisis antes de que ocurran; seguir muy de cerca ("monitorear") el impacto de la crisis y contárselo a la gente; apoyar desde 
los gobiernos los mecanismos de resistencia a las crisis que existen a nivel local; facilitar al máximo la información acerca de los mecanismos de ayuda existentes y hacer campaña para promover la ayuda mutua a escala local y vecinal; convencerse de que "el género importa" y que son las mujeres las que más sufren el impacto de las crisis; y por último, después de la crisis, recuperar

WorLd BANK (2010) The MDGs after the Crisis (Global Monitoring Report 2010), Washington, World Bank, 170 pp.

Quedan sólo cinco años para se agote el plazo establecido por Naciones Unidas para el cumplimiento de los Objetivos de Desarrollo del Milenio (ODM, MDGs en sus siglas en inglés) y sorprende gratamente que con este motivo el Banco Mundial (BM) dedique este informe de la serie anual "Global Monitoring Report" al impacto de la actual crisis global sobre dicho cumplimiento.

Basándonos en el excelente resumen en 10 páginas incluido al principio del Informe, lque comienza con la desafiante pregunta: ¿Cuál es el coste humano de la crisis económica globale) estas son las ocho tesis principales del informe:

Los indicadores de los ODM han mostraban avances significativos antes de la crisis; cuando la crisis golpea, muchos países habían hecho progresos considerables en la reducción de la pobreza extrema. Pero los progresos en los otros ODM venían siendo desiguales. La crisis interrumpió este progreso, pero los efectos no serán visibles durante muchos más años. lo más posible la capacidad de "resiliencia", ...hasta que llegue la próxima. Una vez más, OXFAM nos ofrece una investigación rigurosa e iluminadora.

Las personas interesadas encontrarán la versión completa del texto en la siguiente dirección electrónica: www.oxfam.org.uk/ economiccrisis [José J. ROMERO RODRíGUeZ]

Las crisis anteriores generaron resultados excepcionalmente pobres. Y el impacto de los ciclos económicos sobre los ODM es altamente asimétrico debido a una diversidad de factores.

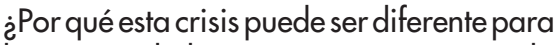
los países de baja renta? Primero, por la mejora en las políticas y en las instituciones ocurrida antes de la crisis. En segundo lugar, porque-a diferencia con crisis anteriores-la crisis actual no fue causada por fallos en las políticas domésticas. Además, los gastos en protección social han sido relativamente protegidos hasta ahora.

Además, la comunidad internacional respondió fuertemente a la crisis. A pesar de los temores generalizados, el acceso de los países en desarrollo a los mercados no ha sido significativamente reducido. Por otro lado, las respuestas aportadas por los bancos multilaterales de desarrollo han intentado proteger lo esencial de los programas de desarrollo, fortalecer al sector privado y ayudar a los hogares pobres. Los donantes aumentaron los volúmenes de ayuda en términos reales durante 2009 .

Aunque la recuperación está siendo más fuerte de lo esperado, las perspectivas para 